\title{
O AGRO E USAID: O CONVÊNIO ESALQ/USP E OHIO UNIVERSITY (1964-1985)
}

\author{
Rodrigo Sarruge Molina ${ }^{1}$
}

\section{RESUMO}

Este artigo tem como objetivo analisar o convênio binacional entre Brasil e Estados Unidos na área rural no período ditatorial. Por meio de documentos históricos de Piracicaba (SP), se revelou os acordos entre a Escola Superior de Agricultura "Luiz de Queiroz" da Universidade de São Paulo (Esalq/USP), a Agência dos Estados Unidos para o Desenvolvimento Internacional (Usaid) e a Universidade Estadual de Ohio (OSU). O convênio fomentou a educação, a pesquisa e a extensão visando a modernização conservadora do meio rural brasileiro, quando essas estatais deram forma e estrutura ao contemporâneo agronegócio. A teoria e metodológica do estudo foi o materialismo histórico dialético.

Palavras-chave: Usaid, Esalq/USP, agronegócio, ditadura.

${ }^{1}$ Universidade Federal do Espírito Santo (UFES), Vitória/ES, Brasil. 


\section{USAID E EDUCACIÓN AGRÍCOLA: EL ACUERDO ESALQ/USP E OHIO UNIVERSITY (1964-1985)}

\section{RESUMEN}

Basándose en fuentes primarias de la Universidad de San Pablo (USP), este artículo analiza las articulaciones mutuas entre la Agencia Internacional para el Desarrollo de Estados Unidos (Usaid), la Universidad Estadual de Ohio y la Escuela Superior de Agricultura "Luiz de Queiroz" de la USP durante el período de la dictadura militar brasileña de 1964-1985. Se describe cómo este convenio inter-institucional fomentó la modernización conservadora del sector rural, dando forma y estructura al contemporáneo agro-negocio, por medio de la educación superior, la investigación científica y la extensión rural. Se constata que dicho convenio trascendió la mera asistencia científico-técnica entre las partes, vehiculando la intervención de Estados Unidos de Norte américa en el Estado brasileño, en el contexto internacional de Guerra-Fría, facilitando el desarrollo lucrativo de sus empresas asentadas en el país sudamericano y moldeando ideológicamente a los cuadros técnicos superiores y los diseñadores locales de política pública rural.

Palabras clave: Usaid, Esalq/USP, agro-negocio, dictadura.

\section{USAID AND AGRICULTURAL EDUCATION: THE CONVENTION ESALQ/USP AND OHIO UNIVERSITY (1964-1985)}

\section{ABSTRACT}

Based on primary sources from the University of São Paulo (USP), this article analyzes the mutual articulations between the United States Agency for International Development (Usaid), the State University of Ohio and the Higher School of Agriculture "Luiz de Queiroz" of the USP during the period of the Brazilian military dictatorship of 1964-1985. It describes how this interinstitutional agreement promoted the conservative modernization of the rural sector, giving shape and structure to the contemporary agribusiness, through higher education, scientific research and rural extension. It is noted that this agreement transcended the mere scientifictechnical assistance between the parties, conveying the intervention of the United States of America in Brazilian State, in the international context of Cold War, facilitating the lucrative development of its companies based in this South American country and influencing ideologically the rural sector.

Keywords: Usaid, Esalq/USP, agribusiness, dictatorship.

\section{USAID ET ÉDUCATION AGRICOLE: L'ACCORD ESALQ/USP ET OHIO UNIVERSITY (1964-1985)}

\section{RÉSUMÉ}

Basé sur des sources primaires de l'université de São Paulo (USP), cet article analyse les articulations mutuelles entre l'Agence des États-Unis pour le Développement International 
(Usaid), l'Université d'État de l'Ohio et l'École Supérieure d'Agriculture "Luiz de Queiroz" de l'USP pendant la période de la dictature militaire (1964-1985). Nous analysons comment cet accord interinstitutionnel a favorisé la modernisation conservatrice du secteur rural, donnant forme et structure à l'agro-industrie contemporaine, à travers l'éducation supérieure, la recherche scientifique et l'extension rurale. Nous constatons que cet accord est allé au delà de la simple aide technico-scientifique entre les parties, puisqu'une intervention des États-Unis a eu lieu au sein de l'État brésilien, ce qui a facilité le développement lucratif de ses entreprises et la pénétration de son idéologie dans le secteur rural brésilien.

Mots-clés: Usaid, Esalq/USP, agro-industrie, dictature. 


\section{INTRODUÇÃO}

Este artigo analisa as relações entre os Estados Unidos, o Brasil e a educação agrícola por meio do convênio internacional traçado entre a Agência dos Estados Unidos para o Desenvolvimento Internacional (Usaid), a Universidade Estadual de Ohio (OSU) e a Escola Superior de Agricultura "Luiz de Queiroz” da Universidade de São Paulo (Esalq/USP) no período da ditadura civil militar (1964-1985).

Para a reflexão aqui proposta, é válido contextualizar que a Esalq/USP está localizada no interior paulista, na cidade de Piracicaba, e que foi inaugurada oficialmente em 1901. Em 1934 deixou de ser administrada pela Secretaria da Agricultura e passou para o domínio da USP. Historicamente, a instituição está atrelada aos Estados Unidos e isso pode ter ocorrido em dois momentos: i) desde sua construção, em 1891, quando o empresário e idealizador da escola, Luiz de Queiroz, contratou Eugene Davenport, professor de agricultura do Michigan Agricultural College para administrar a fazendaescola; ou ii) quando o Professor Clinton D. Smith, da Universidade de Cornell, esteve em Piracicaba entre os anos de 1908 e 1912, ministrando aulas e dirigindo o estabelecimento.

No entanto, as relações entre os dois países foram acentuadas na década de 1960, especialmente após a ditadura civil-militar de 1964, quando foram assinados diversos convênios com o governo norte-americano via Usaid. O contexto histórico brasileiro é o regime militar (1964 a 1985), período em que os setores dominantes dos Estados Unidos (EUA) forneceram apoio ao golpe de Estado de primeiro de abril de 1964, que resultou em 21 anos de ditadura civilmilitar no Brasil. Isso garantiu a efetivação de muitos interesses estratégicos ianques no campo político, econômico, científico e educacional². Nesse sentido, a centenária Esalq/USP, desempenhou um papel de destaque para os EUA na área da educação agrícola na década de 1960, quando as instituições

\footnotetext{
${ }^{2}$ Os EUA ainda apoiam regimes ditatoriais, como é o caso da Arábia Saudita.
} 
estrangeiras Usaid, OSU e a United States Department of Agriculture (USDA), assim como a embaixada e a representação consular se fizeram presentes em Piracicaba3.

\section{CONSIDERAÇÕES TEÓRICO-METODOLÓGICAS}

O presente artigo4 se baseia em documentos históricos localizados na Esalq/USP, especificamente nos acervos: Museu "Luiz de Queiroz"; Biblioteca Central; e Arquivo central (Protocolo). Ademais, consultamos os arquivos do centenário Centro Acadêmico "Luiz de Queiroz" (Calq) (1909) e da ditadura civil-militar (Deops) sob guarda do Arquivo Público do Estado de São Paulo. Os principais documentos encontrados são ofícios legitimados institucionalmente, fotografias, jornais e relatórios.

A pesquisa está inserida na área de estudo das instituições escolares, importante campo de pesquisas para a História e a Educação, visto que, conforme o estudo da história das instituições escolares é fundamental para a compreensão da educação pois, as histórias das escolas é a própria história da educação, - "e não uma mera subdivisão dela" (SANFELICE et al, 2016, p. 28). Assim, partimos do princípio de que a história singular de uma escola pode nos revelar como ocorreu o processo educativo escolar de uma sociedade, pois as instituições escolares são espaços privilegiados para executar a educação das sociedades modernas (ARAÚJO; GATTI JR., 2002).

O principal documento utilizado foi o Relatório Semestral do convênio US-AID-OSU-Esalq de 1964 (USAID/ESALQ, 1964). Trata-se de um extenso relatório oficial, escrito em inglês e em português, que pode ser averiguado nos

\footnotetext{
3 Segundo Dreifuss (1981), essas interferências também visavam barrar a politização rural de esquerda.

4 Este artigo é um dos resultados da tese de doutorado da Faculdade de Educação da Universidade Estadual de Campinas (MOLINA, 2016), concluída com financiamentos da CAPES e do CNPq, em colaboração com a Universidade de Turim, Itália.
} 
arquivos da USP do campus de Piracicaba. Nele existem informações detalhadas do convênio entre a Usaid, a OSU e a Esalq-USP, quando traçaram projetos de pesquisa e extensão para a educação superior agronômica e pesquisa na área das ciências agrícolas, assim como para a agroindústria. O relatório oficial se inicia em 1963, quando nos bastidores ocorriam os preparativos para mais uma intervenção estadunidense no Brasil. Assim,

\footnotetext{
era visível a movimentação dos estrangeiros quando uma delegação da Ohio State University (OSU) percorreu a Esalq/USP, diversos institutos brasileiros, a Secretaria de Agricultura do Estado de São Paulo e os escritórios da Associate Regional Director (ARD) no Rio de Janeiro (MOLINA, 2016, p. 185).
}

Inspirados no materialismo histórico dialético e em intérpretes do Brasil que trabalharam as questões relativas às particularidades do capitalismo brasileiro, nesse artigo, trabalhamos com o conceito de "Modernização Conservadora", que, no recorte histórico analisado - a ditadura civil-militar (1964-1985) -, constituía um projeto político e econômico dos militares, dos empresários e do imperialismo, com o objetivo de modernizar o campo, mesmo que o "moderno" estivesse acompanhado do "arcaico", um fenômeno estrutural do capitalismo desenvolvido no Brasil5, como é o trabalho análogo a escravidão e a aversão a participação popular democrática nas decisões nacionais, como é a violência e repressão de oposições. Na USP de Piracicaba, professores, funcionários e estudantes de esquerda e liberais legalistas da ordem democrática foram delatados, perseguidos e encarcerados. Um dos esalqueanos, Luiz Hirata (Lua) foi torturado e assassinado pela polícia (MOLINA, 2016).

No contexto de preparação do golpe civil-militar de 1964, movimentações e acordos binacionais entre funcionários do governo dos EUA ocorreram no campus da USP de Piracicaba, no entanto, aprofunda-se após a instauração da ditadura, quando a Esalq/USP sofreu interferência direta dos

5 Para mais informações sobre o conceito de "modernização conservadora" ver: Fernandes (1978), Mészáros (2004), Ianni (1979) e Moore Junior (1975). 
estadunidenses via Usaid e USDA, colaborando para a implantação de novos cursos de graduação e de pós-graduação, especialmente na área da energia nuclear aplicada ao campo (CENA) e da modificação de plantas e animais na genética, fomentando o insipiente agronegócio.

Esse foi o retrato do enclave do imperialismo ${ }^{6} \mathrm{em}^{\mathrm{e}}$ que se transformou a economia e a sociedade brasileira, quando o capital estrangeiro esteve presente em quase todas esferas, especialmente na indústria, na agricultura e no setor comercial e financeiro (IANNI, 1979, p. 32). Ademais, o imperialismo também se legitimou por meio da ideologia, que foi intermediada por agências públicas e privadas. Como veremos adiante, um dos campos de atuação foram as instituições escolares7.

\section{A BASE DE OPERAÇÕES DA USAID/OSU NO CAMPUS USP DE PIRACICABA}

A Aliança para o Progresso foi fundada pela gestão Kennedy em 13 de março de 1961, na presença de embaixadores de toda a América Latina, com o objetivo de unir os países do continente visando o desenvolvimento social. No entanto, esse programa era ideologicamente direcionando ao combate contra o comunismo, o que impunha algumas limitações. Essa Aliança estava sob administração e responsabilidade da Usaid, em princípio, sem fins militares, focando em assistência econômica e técnica (FICO, 2008, p. 27-28).

Diante de um quadro global de Guerra Fria, os EUA visaram barrar o avanço da esquerda socialista no continente após a Revolução Cubana de 1959. Por isso, os liberais estadunidenses estimularam a cooperação pan-americana mirando a diminuição da pobreza na América Latina, vista por eles como

\footnotetext{
${ }^{6}$ Segundo Lenin (1987) e Hobsbawm (2004), compreende-se o imperialismo como o grande desenvolvimento histórico de alguns países como causa da exploração, subordinação e subdesenvolvimento de outros países.

7 Ver acordos MEC-Usaid (ARAPIRACA, 1982).
} 
"combustível para o socialismo". Um dos planos foi fomentar o capitalismo no continente por meio do combate ao latifúndio e da criação de planos de reforma agrária e auxílio técnico para o incremento da produção rural. Outras ações estavam concentradas na área social, como planos para a redução da mortalidade infantil e do analfabetismo, assim como outras políticas que objetivavam o crescimento econômico integrado das economias americanas por meio do fomento à industrialização e ao aumento do Produto Interno Bruto dessas nações. Os recursos financeiros para o projeto - que eram da ordem de 20 bilhões de dólares -, seriam divididos entre os Estados Unidos (governo, empresas e fundações) e os países latino-americanos (AYERBE, 2002).

Nesse sentido, os convênios entre universidades e outras instituições foram instrumentalizados pela Usaid para a modernização capitalista da agricultura, pois entre as décadas de 1950 e 1960 a baixa produtividade era considerada o grande empecilho para o desenvolvimento e o progresso do Brasil. Outro fator foi a oportunidade de incrementar o comércio e o American way of life do imperialismo estadunidense em terra brasilis.

Na Esalq/USP, dentre essas agências do governo dos EUA, destaca-se o convênio firmado com a Usaid/OSU, com forte atuação entre as décadas de 1960 e 1970 (1964-1973). Historicamente, esse acordo foi articulado em 19 de abril de 1963, mas foi oficializado em abril de 1964 com a participação do representante brasileiro do ponto IV8, o engenheiro-agrônomo Luiz Simões Lopes. O item II do convênio entre Usaid e Esalq estabelecia: "adaptar o ensino, a pesquisa e a educação do lavrador na Esalq, ao padrão do sistema norteamericano de Land Grant Colleges" (CAPDEVILLE, 1991, p. 38).

Segundo dados bibliográficos de 1975, esse convênio entre estadunidenses e brasileiros proporcionou a visita de professores dos EUA a Piracicaba, que permaneceram por um tempo variável entre dois meses e quatro

\footnotetext{
${ }^{8}$ No contexto de Guerra Fria (1949), visando assegurar a hegemonia dos EUA na América Latina, o ponto IV criou intercâmbio técnico, educacional, cultura e ideológico entre esses países (FGV, 2017).
} 
anos. O mesmo acordo internacional possibilitou a viagem de professores da "Luiz de Queiroz" às universidades norte-americanas, especialmente para cursarem mestrado e doutorado (ESALQ 75, 1975, p. 130).

Assim, de 1964 a 1973, a OSU e a Esalq/USP desenvolveram um programa em colaboração, patrocinado pela Usaid e o Estado brasileiro. Conforme consta no documento oficial, a USP ficou responsável pela Esalq e a OSU ficou com o College of Agriculture and Home Economics e seu órgão associado, The Ohio Agricultural Research and Devolopment Center.

Nesse período, setenta e cinco membros do corpo docente da Esalq/USP fizeram intercâmbio na OSU, sendo que cinquenta e cinco deles concluíram os cursos no estrangeiro e obtiveram o título de $\mathrm{PhD}$ em Agricultura, o equivalente ao curso de doutorado contemporâneo. No mesmo período, de Ohio para a Esalq vieram 60 docentes estadunidenses para trabalhar em programas de ensino, pesquisa e extensão. O grande projeto do intercâmbio foi montar um intenso programa de pós-graduação na "Luiz de Queiroz" e para isso foram fornecidos recursos financeiros e materiais para equipamentos de laboratório e outras "facilidades" (USP, 1988, p. 6).

O foco do intercâmbio entre 1980 e 1983 foi realizar pesquisas em colaboração nas áreas de agricultura, no recém-criado curso de economia doméstica e recursos naturais. Nesse período, por meio do USDA e do Conselho Nacional de Desenvolvimento Científico e Tecnológico (CNPq), quatorze docentes brasileiros realizaram intercâmbio com a OSU e treze estadunidenses da mesma instituição trabalharam na "Luiz de Queiroz". No fim da década de 1980, o convênio concentrou pesquisas nas áreas de biotecnologia e engenharia agrícola (MOLINA, 2016).

Nossos estudos demonstram que, após a liberação de verbas fornecidas pela Usaid para a Esalq/USP, foi instalado um escritório dos representantes dos EUA no campus de Piracicaba. Ambas instituições traçaram um plano para além dos muros da "Luiz de Queiroz", onde passaram a fazer conexões com várias áreas da educação, da pesquisa e da produção agrícola. Com esse intuito, foram 
estabelecidos contatos com os profissionais dos vários institutos de pesquisa, como o Instituto Agronômico de Campinas (IAC), assim como de instituições escolares, como é o caso da Universidade Rural do Estado de Minas Gerais (hoje Universidade Federal de Viçosa), com as divisões da Secretaria de Agricultura do Estado de São Paulo, fazendas, empresas e indústrias (MOLINA, 2016, p. 184).

Os documentos demonstram a preocupação dos técnicos norteamericanos em justificar sua presença no Brasil, o que realizavam com um discurso assistencialista e paternalista. O nosso 'brother sam' (FICO, 2008) afirmava aos acadêmicos, políticos e setores agroindustriais nacionais que objetivava colaborar no aperfeiçoamento do modo de produção dos proprietários rurais brasileiros e de seus trabalhadores, mediante um plano coletivo de tarefas via educação, pesquisa e extensão. Esse projeto foi batizado de Programa Energético de Educação Elevada. Para isso, a "Luiz de Queiroz" foi fundamental, pois o currículo escolar e as pesquisas foram dirigidos a solucionar problemas agrícolas importantes, especialmente em um "esforço coordenado" para informar os lavradores sobre as maneiras e os meios de aumentar a produção e sua renda líquida, seguindo as diretrizes de Ohio (USAID/ESALQ, 1964).

Para fomentar esse movimento de modernização capitalista do campo brasileiro, desembarcou em terras brasileiras o Professor Dr. John H. Sitterley, economista e chefe da missão Usaid/OSU, para o campus da USP em Piracicaba9. Acompanhado de sua esposa e de seus filhos, logo após o desembarque, naquele abril turbulento do golpe civil-militar que depôs o governo democraticamente eleito de João Goulart, Sitterley e sua família se apresentaram ao escritório central do diretor da Usaid no Rio de Janeiro. A primeira semana foi de planejamento em companhia de Kenneth R. Marvin (codiretor do convênio) e outros, quando Sitterley entrou em contato com a

\footnotetext{
9 Além do chefe da missão no Brasil, Sitterley, foram destacados como diretores Renato Catani (Esalq/USP) e Kenneth R. Marvin, que exercia o cargo de Associate Regional Director (ARD).
} 
dinâmica de operações da base central no Rio de Janeiro e familiarizou-se com suas responsabilidades (Fig. 1).

Figura 1 - Professores da Usaid/OSU e suas famílias no campus da USP de Piracicaba (s/d).

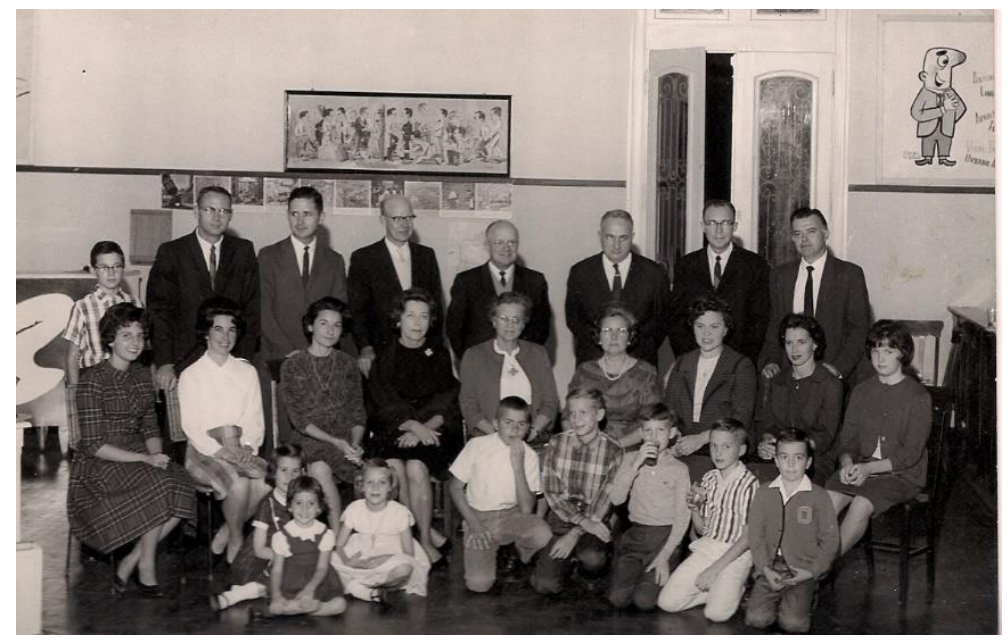

Fonte: acervo do Museu "Luiz de Queiroz".

Consta no relatório oficial (USAID/ESALQ, 1964) que, durante esse período de preparação no Rio, Sitterley também viajou para a cidade de São Paulo em companhia de R. Newberg para proferir uma conferência com o Secretário da Agricultura de São Paulo, Oscar Thompson, professor da Esalq. Durante o encontro na capital paulista, o chefe da missão Usaid/OSU e os demais técnicos estrangeiros colocaram-se à disposição do governador de São Paulo, Ademar Pereira de Barros, em tudo o que fosse preciso, com o objetivo de aumentar a produção e a renda agrícola dos produtores paulistas, que também eram proprietários de milhões de hectares em outras unidades da federação, especialmente Mato Grosso e Paraná (GRAZIANO DA SILVA, 1982, p. 69).

Após sete dias de instruções no Rio de Janeiro, Sitterley, junto de sua família, chegou a Piracicaba no dia 13 de abril de 1964. Após se estabelecer na cidade, iniciou os trabalhos de preparação da infraestrutura para a chegada de uma comitiva de cerca de oito professores da Usaid/OSU, que também se instalariam em Piracicaba com suas famílias. Esses agentes comporiam o 
primeiro grupo de trabalho da Usaid no "campus da USP de Piracicaba após a deflagração do golpe civil-militar (MOLINA, 2016, p. 187).

Chegando ao campus de Piracicaba, Sitterley foi amparado pelo Professor Renato Catani, codiretor do convênio, e pelo diretor e Professor Hugo de Almeida Leme. A maior parte do tempo, nos dois meses que se seguiram, foi reservada para conhecer a Esalq/USP, assim como as normas do convênio e as "facilidades locais", buscando residências adequadas, mobília e veículos para o grupo da Usaid/OSU que chegaria no dia primeiro de julho de 1964 (USAID/ESALQ, 1964). Também houve o cuidado quanto à organização do escritório central de Piracicaba e de parte do quadro de funcionários locais, sempre supervisionado por agentes estadunidenses deslocados das bases de operação do Rio de Janeiro e de São Paulo que, para além de supervisionar, também auxiliavam nesses e em outros trabalhos de Sitterley (USAID/ESALQ, 1964).

Segundo os documentos oficiais (USAID/ESALQ, 1964), entre 13 de abril e 27 de junho de 1964 foram proferidas conferências com os membros da cadeira de Economia Rural, com o objetivo de discutir o currículo, as pesquisas e os planejamentos. Também nesse período, junto de membros da Esalq/USP, Sitterley realizou várias visitas ao gabinete da Secretaria de Agricultura de São Paulo, visando traçar planos articulados entre as atividades internas do campus de Piracicaba, a Usaid/OSU e os setores ligados à pesquisa e à cadeia produtiva agroindustrial.

Após o sinal positivo do Secretário da Agricultura, o convênio binacional passou a trabalhar na conexão com esses setores produtivos e com outras instituições educacionais e científicas. Como as fontes demonstram, no dia quatro de maio foi realizada uma conferência com o norte-americano Sherman Leonard e o brasileiro Rodolpho Camargo no Instituto de Tecnologia dos Alimentos em Campinas, a fim de planejar a cooperação e a participação dos campineiros, em especial no campo da pesquisa com o convênio traçado entre Piracicaba e Ohio (USAID/ESALQ, 1964). 
No entanto, para que todo esse processo de intervenção dos estadunidenses ocorresse, demandou-se uma infraestrutura física. Em 1966, o diretor Hugo de Almeida Leme atendeu à solicitação dos estrangeiros e disponibilizou um espaço no recém-inaugurado prédio da biblioteca do campus de Piracicaba, que foi financiado pela Fundação Rockefeller, pelo convênio Usaid/OSU e pelo governo federal do Brasil. No relatório oficial, o espaço destinado aos estrangeiros na biblioteca era denominado de Centro de Informações e tinha a função de ser uma base de operações dos agentes estadunidenses da Usaid e da OSU a partir de Piracicaba, contando com funcionários, abastecimento de equipamentos e uma série de facilidades locais (USAID/ESALQ, 1964, p. 2).

$\mathrm{Na}$ época, estava em pauta o desenvolvimento de um programa de tradução de livros acadêmicos da área das ciências agrícolas dos EUA para ser implantado nas universidades brasileiras. Esse projeto era desenvolvido e patrocinado pelo Escritório Técnico de Agricultura dos EUA no Rio de Janeiro (ETA-Usaid). Para isso, foi solicitado a cada um dos 23 catedráticos da Esalq/USP a leitura de uma lista de livros dos EUA e a seleção de três volumes para a tradução, além de uma sugestão de uma pessoa que traduzisse o material para o português. Após essa consulta, os técnicos do convênio formularam uma lista e a enviaram ao Escritório Técnico de Agricultura (ETA-Usaid) no Rio de Janeiro, tendo sido posteriormente apresentada à Associação de Escolas Superiores de Agricultura Brasileiras. 
Figura 2 - Capa do livro estadunidense introduzido na Esalq/USP.

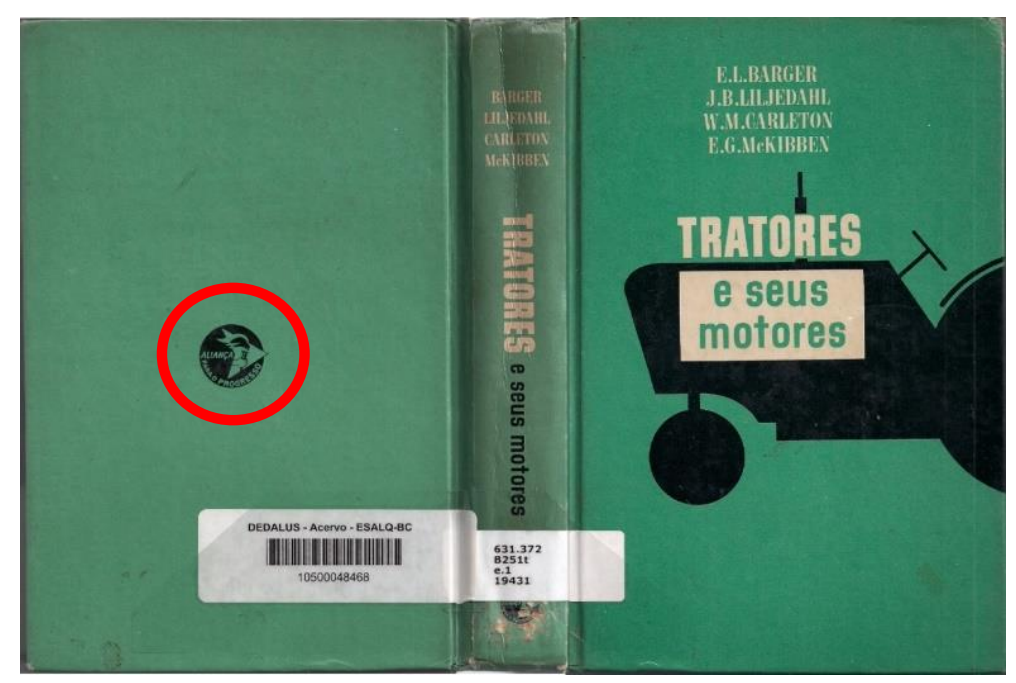

Fonte: acervo da Biblioteca Central da Esalq/USP.

Conforme se vê na Figura 2 acima, o presente material didático foi formulado pelo governo dos EUA e utilizado na Esalq, dentro do convênio Usaid/OSU e USP/Esalq (BARGER, 1966). Editado originalmente em $1963 \mathrm{em}$ Nova Iorque, a presente edição foi publicada em 1966 em São Paulo, com participação do programa Aliança para o progresso (símbolo interno à circunferência vermelha). O livro ainda se encontra em uso na biblioteca da instituição. Na contracapa (Figura 3), poderemos encontrar mais informações (MOLINA, 2016, p. 190). Esse livro faz parte do acervo da Biblioteca Central da Esalq/USP. 
Figura 3 - Folha de rosto do livro estadunidense introduzido na Esalq/USP.

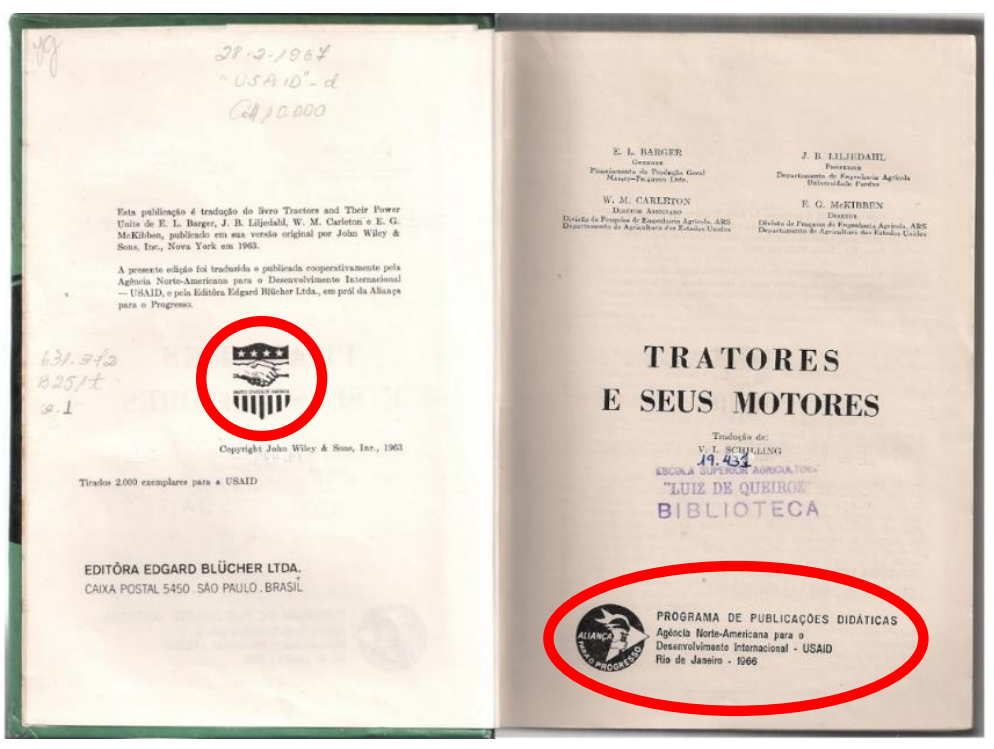

Fonte: acervo da Biblioteca Central da Esalq/USP.

Na contracapa, lê-se: “[a] presente edição foi traduzida e publicada cooperativamente pela Agência Norte-Americana para o desenvolvimento internacional - Usaid e pela editora Edgard Blucher LTDA em prol da 'Aliança para o progresso' " (BARGER, 1966). Logo abaixo, na contracapa, localizada à esquerda, pode-se observar a publicidade da Usaid, que é retratada com o seu símbolo oficial, um brasão desenhado que reproduz um cumprimento, com duas mãos, simbolizando a amizade entre os "povos amigos" em torno da bandeira dos Estados Unidos (símbolo interno à circunferência vermelha). Já na folha de rosto podemos observar o símbolo da Aliança para o progresso, retratada com uma tocha clareando a América Latina (símbolo interno à elipse vermelha) (MOLINA, 2016, p. 191). Esse livro faz parte do acervo da Biblioteca Central da Esalq/USP.

Entre outros assuntos tratados, diagnosticou-se a necessidade de transformar e ampliar as capacidades de alojamentos na escola (dormitórios e refeitórios), assim como de implementar um programa de pós-graduação, com especial destaque para a área de economia rural.

Para compreender melhor esse plano de intervenção ideológica e de 
ajuda técnica da Usaid na Esalq, é valiosa a leitura de um extenso relatório chamado Country Analisis and Strategy Paper (Casp), estudo em que os objetivos estratégicos dos EUA no Brasil na época da ditadura foram sintetizados. Na versão crítica, escrita em 1969, prioridades são apontadas: apoiar a estabilidade e o crescimento do Brasil por meio de uma relação amigável com os EUA; manter, proteger e expandir os investimentos das empresas dos EUA no Brasil; fomentar a cooperação militar entre os países visando a segurança interna e externa dos EUA; e, quando necessário, usar o Brasil no campo internacional para assegurar os interesses dos EUA ${ }^{10}$ (MOTTA, 2014, p. 112-113).

Com relação à área da educação, os principais objetivos eram influenciar no processo de modernização das instituições escolares e na formação de seus estudantes e professores para que fossem simpáticos aos EUA, sendo essa uma maneira de aumentar as boas relações entre os países, já que se tratavam de importantes frações da elite cultural. Concluíam, ainda, que para eliminar a presença da esquerda, principalmente do ponto de vista cultural e ideológico, era essencial ser vitorioso nas batalhas travadas na formação de valores da comunidade escolar e acadêmica e, por isso, existia a importância estratégica de traduzir livros estadunidenses para uso nas salas de aula e bibliotecas, criar convênios e intercâmbios entre as universidades do Brasil e EUA, visando especialmente o treinamento de professores e pesquisadores brasileiros em território norte-americano (MOTTA, 2014, p. 114).

\section{OS PROFESSORES DA USAID/OSU EM AÇÃO: COMPRESSÃO, INTERVENÇÃO E COOPTAÇÃO}

Os primeiros professores do convênio Usaid/OSU que chegaram a Piracicaba com suas famílias eram: Clyde Alissin (Fitopatologia), Alvin I. Moxon

\footnotetext{
${ }^{10}$ Sobre esse assunto, ver Leacock (1990).
} 
(Nutrição dos Animais), John I. Parsons (Forragem e Pastagens), Charles Triplehorn (Entomologia Econômica) e Clair Young (Extensão e Métodos). À ocasião, apresentações formais com o diretor da Esalq/USP, Eurípides Malavolta, o corpo docente, os assistentes dos técnicos e o pessoal das áreas anteriormente citadas foram providenciados (USAID/ESALQ, 1964, p. 5). Assim, após a chegada e a instalação na cidade, a equipe de Ohio foi convocada para a embaixada dos EUA no Rio de Janeiro e no consulado em São Paulo. Juntamente com os esalqueanos, visitas guiadas foram realizadas para que os estrangeiros inspecionassem os recursos da "Luiz de Queiroz". Os professores também efetuaram viagens externas em variadas instituições para diagnosticar a situação dos recursos humanos disponíveis nas diversas áreas das Ciências Agronômicas do estado paulista.

Segundo o relatório, em setembro, outros três técnicos estadunidenses de Ohio também chegaram a Piracicaba para se juntar ao grupo já instalado. Eram respectivamente: Fred Deatherage, do setor de Tecnologia dos Alimentos, Floyd Herum e Howard Steele, ambos da Economia Agrícola, o último acompanhado da esposa e três filhos (USAID/ESALQ, 1964, p. 5). Muitas conferências foram realizadas entre os técnicos estrangeiros e seus assistentes no campus de Piracicaba. Outra série de conferências e reuniões fechadas foram realizadas com autoridades de diversas instituições do Estado. Também consta a realização de reuniões científicas, seminários e viagens de estudos em fazendas por todo o Brasil.

Em 26 de agosto de 1964, o plano de trabalho foi produzido, frisando os objetivos do convênio internacional e de como obter progresso no cumprimento da missão. Cópias foram enviadas ao Associate Regional Director, Kennth R. Marvin, e ao Codiretor da Esalq/USP. Entretanto, um item do projeto chama atenção: o desenvolvimento de projetos individuais semelhantes aos desenvolvidos nos EUA para cursos breves, seminários, pesquisas e projetos de extensão.

Em 18 de setembro, depois de numerosas e longas conferências com 
professores esalqueanos, com os contrapartes e técnicos de outros institutos, o projeto foi reelaborado com a inclusão da parte orçamentária. Os 23 projetos envolveram, aproximadamente, o gasto anual de 60.587.000 de Cruzeiros para a Esalq/USP e 83.055.000 ${ }^{11}$ para a Usaid ${ }^{12}$. As discussões finais para a aprovação dos projetos e dos orçamentos foram realizadas no dia 29 de setembro no Rio de Janeiro e um compromisso "experimental" foi aprovado em dois de outubro de 1964 (USAID/ESALQ, 1964).

O conteúdo final do projeto destacou as seguintes diretrizes gerais do convênio entre a Usaid/OSU e a Esalq/USP: 1 - Estudo minucioso da situação agrícola paulista; 2 - Desenvolvimento de um projeto piloto para o estado de São Paulo; 3 - Treinamento de supervisores do fomento; 4 - Revisão dos currículos da escola; 5 - Análise e atenção especial à criação do curso de sociologia rural, economia doméstica e extensão rural; 6 - Familiarização dos estadunidenses com a produção agrícola do Brasil (processos de produção e comercialização); 7 - Estudo, reformulação e criação de cursos de pós-graduação; 8 - Intervenção e patrocínio nas pesquisas, com a promoção de seminários, estudo intensivo das atividades e organização da extensão agrícola.

Ainda nesse ano de 1964, o relatório também destaca a breve visita da consultora em economia doméstica, Eva Wilson ${ }^{13}$, que desembarcou no dia 14 de agosto em Piracicaba, quando contribuiu para a criação do curso de economia doméstica ${ }^{14}$ na Esalq/USP, por meio de uma série de conferências. Sempre acompanhada do Diretor Malavolta e por membros do corpo docente, a consultora centralizou sua atuação na revisão do currículo do curso de economia

\footnotetext{
${ }^{11}$ Segundo cálculos do economista Prof. Dr. Henrique Braga (Ufes), no ano de 2013, os valores equivaleriam a 566.6 de Reais para a Esalq/USP e 776.730 de Reais para a Usaid. Porém, o resultado deve ser usado com cautela porque se trata de uma aproximação do valor da época aos preços de hoje. Existem questões que devem ser levadas em conta, como o poder de compra das moedas no decorrer da História.

${ }^{12}$ Originalmente o relatório menciona: "US-AID-B".

${ }^{13}$ Eva Wilson foi homenageada pela turma de 1971 do curso de ciências domésticas que contou com o ministro Jarbas Passarinho como paraninfo (ver quadro de formados da Esalq no Prédio Central).

${ }_{14}$ Criado em 1967 e desativado em 1991.
} 
doméstica e propôs algumas mudanças nos materiais didáticos, no perfil dos professores e na infraestrutura do curso (USAID/ESALQ, 1964, p. 6). Após três anos dessa visita, o curso foi inaugurado oficialmente em 1966.

Segundo dados de 1975, o convênio internacional decidiu que o currículo em economia doméstica seria formulado com um objetivo central: contribuir para solucionar o problema da nutrição dos habitantes da zona rural. A disposição do currículo também enfatizava

a ênfase nas disciplinas que ajudavam a formação de economistas que desenvolvessem a capacidade de raciocínio independente para a tomada de decisão e priorização de solução de problemas para a zona rural e com isso, complementariam e auxiliariam os agrônomos, dando às deste a dimensão social e humana (MALAVOLTA, 1975, p. 46).

Um dos professores a deixar seu relato das experiências binacionais foi o Dr. Clyde Allison da área da Fitopatologia. Após o resultado positivo de adaptação entre o técnico estadunidense e os brasileiros, seu principal objetivo foi dar uma direção às pesquisas realizadas na Esalq/USP, desenvolver um programa de pós-graduação, incentivar os docentes e os alunos que estivessem alinhados às políticas oficiais do convênio Usaid/Esalq e, por fim, guiar o departamento na direção da ampliação da extensão agrícola. Conforme Allison relatou, diversos alunos estavam sendo examinados quanto a sua qualificação e seu interesse na área da Fitopatologia, visando cooptá-los para os projetos desenvolvidos entre Ohio e a "Luiz de Queiroz". No entanto, somente "os realmente interessados” seriam escolhidos (USAID/ESALQ, 1964, p. 8). Questões pedagógicas também foram debatidas em conferências com os professores locais, especialmente as relativas aos "métodos de ensino". Em Piracicaba, Allison permaneceu oito anos como professor visitante da então 11a Cadeira de Fitopatologia ${ }^{15}$.

15 Sobre a ingerência dos EUA, reportou Paulo Carvalho que desde a década de 1920 os estadunidenses atuam nesse departamento, quando foi contratado o Prof. Edwin E. Honey 
O Professor Alvin Moxon, também agente da Usaid, chegou em Piracicaba em 27 de junho de 1964, momento em que se empenhou nos estudos da língua portuguesa visando interagir e comunicar-se com a comunidade acadêmica e empresarial, pois naquela época não era comum encontrar brasileiros que compreendessem a língua inglesa. Articulou-se na capital paulista com o Instituto da Produção Animal e o Escritório Geral do Congresso Internacional de Pastagens. Na cidade de Matão (SP), conectou-se com a fazenda de pesquisas do Research Institute (IRI) ${ }^{16}$, outra instituição do governo dos Estados Unidos que também operavam em solo brasileiro com objetivos variados. (USAID/ESALQ, 1964, p. 9).

Outro professor da Usaid foi o Dr. John I. Parsons, que chegou a Piracicaba no dia primeiro de julho de 1964. Acostumado com as temperaturas geladas de Ohio, encontrou nesse ambiente de "inverno caipira" um clima favorável para estabelecer-se tranquilamente com seus cinco filhos e sua mulher em uma bela e espaçosa casa, mobiliada e abastecida graças a Sitterley, chefe do grupo estadunidense, que havia preparado, desde abril, uma infraestrutura para a chegada de seus compatriotas e colegas da Usaid/OSU no interior paulista. Assim, em decorrência da infraestrutura pré-estabelecida, Parsons teve a possibilidade de iniciar prontamente os trabalhos de ensino, pesquisa e extensão. Assim, cumprindo as determinações do convênio, o professor também atuou fora dos muros da Esalq/USP, especialmente na sede do Congresso Internacional de Pastagens e no Inter-American Institute of Agricultural Science (OAS).

Com relação a área da economia agrícola, o responsável foi o Prof. Dr. John Sitterley, que também era chefe do grupo da Usaid em Piracicaba, em que por meio da base de operações instalada nas dependências da antiga biblioteca da Esalq/USP, pôde coordenar uma série de projetos internos e externos à escola. No Brasil, Sitterley esteve em contato com seu compatriota Dr. Raleigh

${ }^{16}$ O IRI dos EUA é uma agência de pesquisa, com objetivos amplos na América Latina (SILVA, 2011, p. 6). 
Fosbrink, pertencente à U.S. Land Grant Association, uma instituição estadunidense que atua desde 1862 na área da educação e da pesquisa agronômica e que também estava intervindo em solo brasileiro.

Em 18 de agosto de 1964, recebeu uma comitiva da Fundação Ford na Esalq/USP (MICELI, 1993). O grupo visitante, que era composto pelos doutores Kunsella, Mattias e Swanson, objetivava articular, junto do corpo docente esalqueano e aos técnicos da Usaid/OSU, as possibilidades existentes no Brasil para acelerar o desenvolvimento agrícola por meio da educação agrícola de nível secundário, em uma espécie de ensino médio, técnico e agronômico. Para tanto, sugeriram a criação de um curso piloto no campus da USP de Piracicaba, utilizando a estrutura já existente na instituição que era reconhecida como uma das mais avançadas da América Latina.

Para debater o tema da educação secundária na agricultura brasileira, ocorreram uma série de conferências com o Professor Erico da Rocha Nobre, catedrático (economia rural), o Professor Doutor Rubens Dias, diretor da divisão de economia agrícola representando a Esalq/USP e os professores Ken Dermott e Erly Brandão, representando a Universidade de Viçosa/MG, além dos norte-americanos, professores Steele, Young e Sitterley, que ficaram responsáveis por apresentar os trabalhos, conduzir os debates e produzir o relatório final (USAID/ESALQ, 1964).

Outro estadunidense que trabalhou para a Usaid/OSU em Piracicaba foi Charles Thiplehorn, responsável pela área da entomologia, empenhando-se em alterar as condições de armazenamento de cereais no país, como o milho e a soja. Para além de São Paulo, esses projetos também foram articulados com diversos centros de pesquisa e fazendas por todo o Brasil, especialmente com engenheiros agrônomos do Rio de Janeiro e de Viçosa-MG. Triplehorn articulou junto dos departamentos de Entomologia e Patologia das plantas cursos de curta duração com entrada restrita a professores e a agrônomos de perfil vocational-agricultural (VO-AG), ou seja, segundo a filosofia meritrocrática estadunidense, as vagas nos cursos eram limitadas aos candidatos 
especialmente selecionados, sendo o critério de seleção a verdadeira vocação agrícola dos candidatos (USAID/ESALQ, 1964, p. 14).

Outro agente da Usaid em Piracicaba foi Clair W. Young, responsável pela área de Extensão e Métodos. Conforme consta nos documentos históricos, nos primeiros meses de trabalho no Brasil ele esteve articulado em um projeto com diversas instituições nacionais e norte-americanas, que objetivavam compreender o panorama da educação agrícola do estado de São Paulo.

Organizado especialmente na forma de conferências, o projeto Estudo Minucioso Sobre a Situação da Educação Agrícola do Estado de São Paulo compreendia as seguintes instituições: Esalq/USP; técnicos da Usaid de São Paulo, Rio de Janeiro, Wisconsin e Purdue; Fundação Ford, o Clube 4- $\mathrm{H}^{17}$, a Cooperativa Agrícola de Cotia/SP, o Centro de treinamento (Cetrec) e Técnicos do Research Institute (IRI) de Campinas/SP. Destaca-se, ainda, a presença da Federação da Juventude em São Paulo, de burocratas do consulado dos EUA em São Paulo e também do conjunto de funcionários a serviço dos EUA em exercício no interior paulista, especialmente os das cidade de Bauru, Piracicaba e Matão, denominados no documento de "funcionários do fomento18" (USAID/ESALQ, 1964, p. 15).

Além de conferências com as instituições acima, para compreender o panorama da educação agrícola do estado de São Paulo, em 1964, Young descreve que também usou uma série de materiais escritos por essas entidades, muitos deles confidenciais. Entre eles estavam os textos elaborados pela Associação Brasileira de Crédito e Assistência Rural (Abcar) e gráficos da Secretaria de Agricultura de São Paulo. Também foram usados os relatórios dos convênios entre a Usaid e outras universidades brasileiras, pois, assim como a

$17 \mathrm{O}$ Clube 4-H (fundado em 1902) pertence ao USDA. Hoje agrupa 90.000 clubes com 6,5 milhões de jovens de cinco a 19 anos por todo o mundo. O principal objetivo é promover a aprendizagem prática da agricultura nas escolas públicas e privadas visando influenciar especialmente a juventude rural (FOUR-H, 2016).

${ }^{18}$ Entende-se por "funcionários do fomento" o conjunto de empregados nacionais e estrangeiros (Universidades, Associações, Institutos, Prefeituras, Empresas) articulados aos projetos dos EUA no Brasil. 
Esalq/USP, outras instituições universitárias brasileiras estavam em convênio com a Usaid na área da agricultura, com destaque para os convênios entre a Usaid-Purdue University e a Universidade Rural do Estado de Minas Gerais (UREMG, hoje UFV) e entre Usaid-University of Wisconsin e a Universidade Federal do Rio Grande do Sul (UFRGS).

Para além dessas conexões exteriores e não perdendo de vista seu principal objetivo, "a compreensão do sistema educacional agrícola paulista" (USAID/ESALQ, 1964) Young também frequentou disciplinas nos cursos de graduação da Esalq/USP para coletar informações acerca dos métodos de ensino utilizados pelos professores. Como resultado, Young traçou três objetivos e metas a serem alcançadas para a educação agronômica paulista sendo eles respectivamente: 1 - Intervenção na educação com parceria da Secretaria da Agricultura de São Paulo; 2 - Influência dos projetos em curso na Esalq, acrescentando ou anulando ideias; e 3 - Intervenção no Centro de Treinamento de Campinas ${ }^{19}$ (Cetrec).

19 O foco dos treinamentos em Campinas se dava sobre os seguintes temas: "modernas técnicas de supervisão"; "relações humanas"; "comunicações" e "administração", tudo dentro da ideologia da teoria do capital humano (ARAPIRACA, 1982) que, por meio de uma visão "tecnicista", objetivava convencer os agrônomos, os produtores rurais e os demais setores ruralistas de que, dentro da concepção capitalista, o investimento em educação é um fator de crescimento econômico, assim como, individualmente, os sujeitos que investissem na própria educação também estariam potencializando sua capacidade de ganhos e empregabilidade. 
Figura 3 - Professor do convênio Usaid/OSU lecionando em inglês no campus da USP de Piracicaba (s/d).

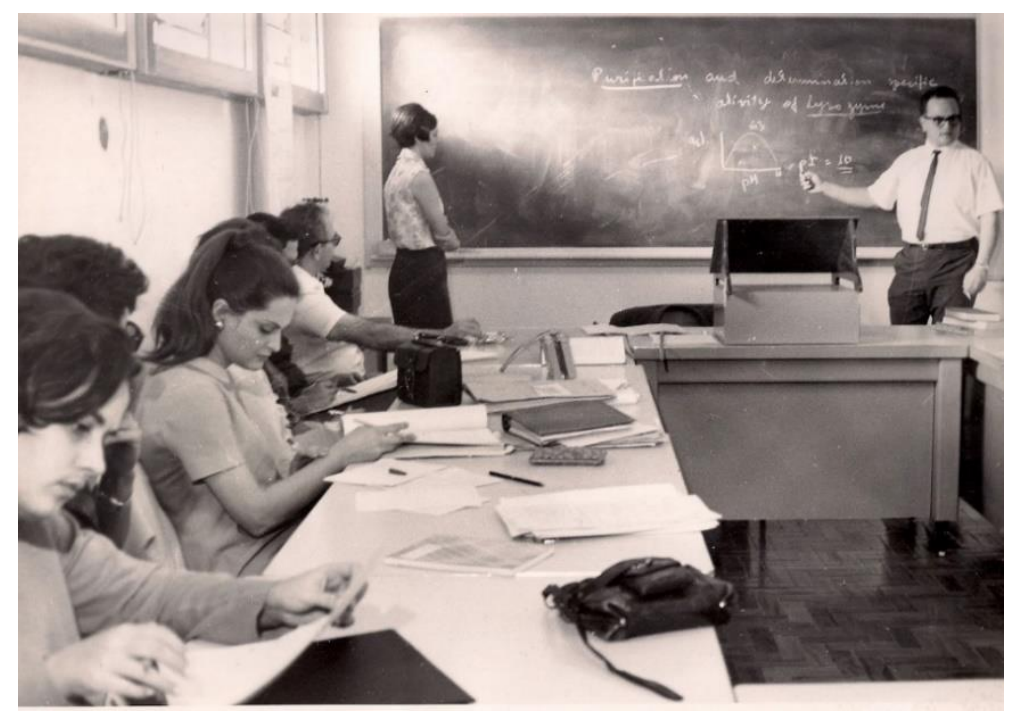

Fonte: acervo do Museu "Luiz de Queiroz".

Nesse sentido, para caminhar em direção ao primeiro objetivo foi reforçada a ideologia educacional dos EUA na escola. Especialmente fundamentados na teoria do capital humano (ARAPIRACA, 1982), Young visou o desenvolvimento de um tipo "eficiente" e "realista" de assistência educacional às famílias dos fazendeiros paulistas. Para caminhar nesse sentido, foi implantado um programa de assistência do tipo "extensão" às famílias rurais. Além disso, Young também ressaltou a necessidade de alterar o sistema de gerenciamento de todos os recursos da área da educação, o que demandaria a ampliação do quadro de funcionários da Casa da Lavoura, com especialistas nas áreas de economia doméstica e trabalho focado na juventude. Para isso, esteve em curso no ano de 1964 um plano de longo alcance para o desenvolvimento de um projeto piloto no estado de São Paulo, usando o campus de Piracicaba para a constituição de uma escola-fazenda padrão. Para tanto, foi acionado o plano de substituição (demissão) dos quadros dirigentes, ou das autoridades responsáveis, e a contratação de recursos humanos qualificados e técnicos sintonizados com as propostas estadunidenses, ou seja, com trabalho focado na juventude rural por meio da extensão via sociologia rural e economia doméstica, 
sob apoio dos funcionário do Escritório Técnico de Agricultura da Usaid em São Paulo (USAID/ESALQ, 1964, p. 16).

Para isso, Young procurou influenciar os projetos em curso da Esalq, acrescentando ou anulando ideias. $\mathrm{O}$ foco foi especialmente concentrado na análise e na formulação dos conteúdos do curso de sociologia rural e de extensão rural, visando determinar as técnicas de ensino em sala de aula com o auxílio de matérias atualizadas, especialmente as utilizadas nos cursos de agricultura de Ohio. Atrair pesquisadores e professores esalqueanos para realizarem intercâmbio com professores e pesquisadores de Ohio e suas demais parceiras também era o objetivo (USAID/Esalq, 1964, p. 17).

Ainda, em 1968, trabalhou na base norte-americana de Piracicaba o Dr. Walter Harvey, destacado professor da OSU. Era o quarto ano do convênio entre a Esalq e a Usaid/OSU, um período de alterações no convênio internacional, ocorrendo rodízio de alguns professores, principalmente em decorrência dos contratos de trabalho que eram planejados para funcionar por dois ou quatro anos (USP/ESALQ, 1968). O geneticista Harvey colaborou em Piracicaba entre novembro e dezembro de 1968, período em que visitou diversas instituições estatais de São Paulo, principalmente o Departamento de Produção Animal e algumas fazendas e agroindústrias particulares, ocasião em que discutiu os problemas referentes à mutação genética dos animais.

No período em que esteve no campus, em conjunto com a comissão de bolsas, trabalhou para selecionar dois alunos do quarto ano para ir aos EUA para a realização de um programa de treinamento totalmente patrocinado pela Usaid. Nesse contexto, o convênio binacional financiou muitos equipamentos destinados ao Centro de Informações, base operacional dos norte-americanos no campus de Piracicaba e também para diversas áreas, instituições e organizações não necessariamente associadas ao convênio entre a Esalq e a Usaid (USP/ESALQ, 1968).

A Figura 5, a seguir, mostra um equipamento denominado addressograph, uma espécie de impressora que fabricava rótulos, 
confeccionada pela empresa Addressograph-Multigraph Corp. dos Estados Unidos, localizada em Cleveland, Ohio. Ademais, lê-se no equipamento a inscrição: "PATENT CANADA 1961". Em 2012, essa máquina era uma peça de decoração do Centro Acadêmico (CALQ) da Esalq/USP. Já à direita, a imagem mostra a ampliação do símbolo da Usaid impresso no equipamento.

Figura 5 - Addressograh (à esquerda) e ampliação do símbolo da Usaid (à direita).

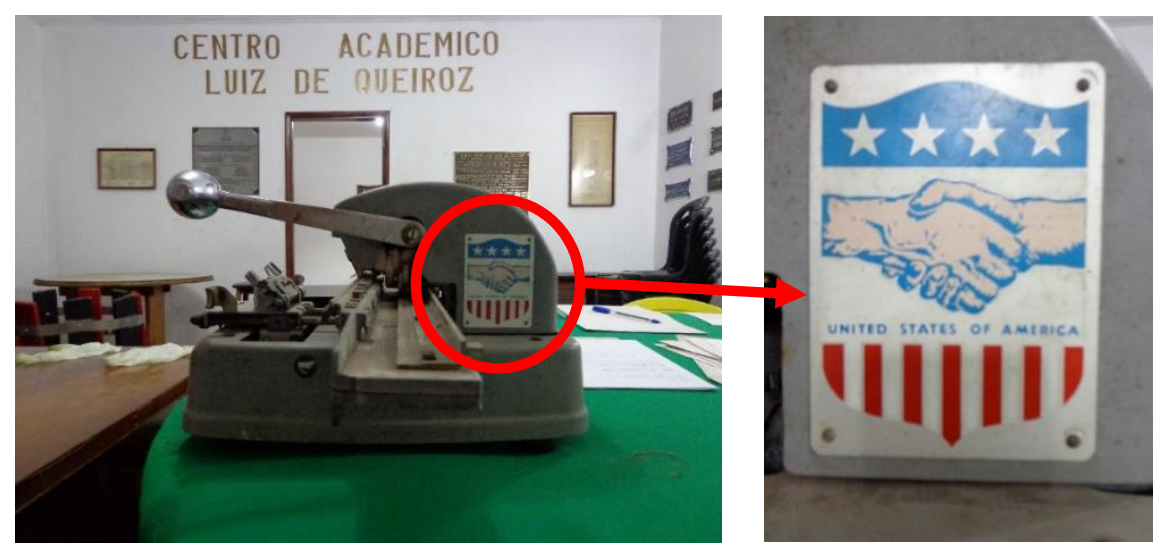

Fonte: acervo do autor, 2012.

Os estadunidenses trabalharam a partir de Piracicaba com grande intensidade até 1974, mesmo ano em que a Usaid desativou a maior parte de seus programas e escritórios no Brasil, solicitando o retorno de seus agentes para Washington. Tratou-se de um contexto internacional conturbado com a Guerra do Vietnã, a crise do petróleo e escândalos políticos como o impeachment de Richard Nixon e as denúncias internacionais de torturas e violações dos direitos humanos pela ditadura brasileira sob apoio do governo dos EUA (MOLINA, 2016, p. 228).

Assim, após o fim dos convênios entre a Usaid/OSU e a Esalq/USP, a Universidade de Ohio voltou a firmar tímidos convênios com a "Luiz de Queiroz" em 1980, aparentemente independentes da Usaid e distantes dos "anos dourados", quando os dólares chegavam com facilidade ao campus de Piracicaba. 


\section{CONCLUSÃO}

No Brasil, as intervenções imperialistas dos EUA, que ocorriam desde o início do século XX, foram fortalecidas e intensificadas após 1959 em decorrência da Revolução Cubana e de movimentos de libertação nacionalistas, socialistas e nacional-desenvolvimentistas, que ameaçavam a hegemonia comercial e cultural de Washington em sua tradicional zona de influência: a América Latina.

Para que essa hegemonia continuasse em um quadro de ebulição da Guerra Fria, como foi, por exemplo, a crise dos mísseis de 1962, os EUA intensificaram e fortaleceram sua presença na América Latina por meio de suas agências governamentais, desde o serviço secreto (CIA) até agências de auxílio técnico-econômico como foi a Usaid e a Aliança para o progresso.

Nesse contexto, em coligação com os estadunidenses, a ditadura brasileira passou a olhar a educação como uma questão de segurança interna. Sob a égide da ideologia da interdependência (Guerra Fria e subordinação do Brasil aos EUA), todo o aparelho estatal foi reordenado para atender àquilo que passou a ser chamado de "imperativo da segurança nacional", ou seja, caçar e eliminar os inimigos e opositores do regime e impor à força uma modernização capitalista e conservadora de toda a sociedade, como foi o caso da educação agrícola e da gênese do nosso agribusiness.

Apesar do discurso ufanista da ditadura, o capital monopolista enfraqueceu a soberania do Estado brasileiro, sendo que os negócios com as terras, os recursos naturais, a agroindústria, a educação e a ciência foram apenas um dos desdobramentos da violenta acumulação do capital imperialista, quando o aparato militar garantia a "ferro e fogo" a "paz" e a tranquilidade para os negócios da burguesia nacional e internacional.

Grosso modo, as intervenções estadunidenses foram bem-sucedidas. Combateu-se as propostas nacional-desenvolvimentistas brasileiras (GetúlioJango), a influência da esquerda (PCB e Ligas Camponesas) e reforçou-se o 
papel coadjuvante tupiniquim no mundo "ocidental". A modernização conservadora da economia capitalista foi realizada, rendendo altos lucros para as empresas dos EUA e setores burgueses locais, mas as desigualdades sociais não foram tocadas, mas acentuadas. Os financiamentos da Usaid reforçaram os laços entre os dois países, especialmente por meio da ideologia estadunidense anticomunista e seu American way of life.

Antecessores aos pactos MEC-Usaid, os acordos entre a Usaid/OSU e a Esalq/USP promoveram o desenvolvimento da educação, da ciência e da extensão rural direcionados para a expansão da agroindústria capitalista, especialmente no estado paulista. Porém, isso não significou exclusividade, pois os estadunidenses estabelecidos na base operacional de Piracicaba/SP também atuavam em vários estados e países da América Latina, tanto em instituições estatais quanto nos setores agroindustriais particulares, ou seja, o convênio foi porta de entrada para outras atividades que iriam além da educação e da ciência.

Uma das grandes preocupações do convênio binacional foi articular a educação superior agrícola e a pós-graduação ao processo de modernização capitalista do campo brasileiro, o que compreendemos como a gênese do processo de constituição do contemporâneo agronegócio high tech brasileiro, quando entre 1964 e 1985, sob ditadura, a Esalq/USP colaborou com o aumento produtivo de diversas commodities, como foi a mutação genética de sementes e de animais, assim como o desenvolvimento de tecnologias rurais, entre outros.

Apesar disso, constatamos que, mesmo que travestidas de "verde e amarelo", a educação e a ciência sofreram forte influência da concepção estrangeira. Apesar dos investimentos públicos-estatais brasileiros serem hegemônicos, a comunidade acadêmica foi atraída pela concepção estadunidense de produção agrícola e sua ideologia baseada no liberalismo capitalista. Isso foi reforçado pelo grande montante de dólares que entrava na instituição, ao mesmo tempo em que os norte-americanos penetravam na estrutura estatal local e nacional, o que causou grande celeuma, pois os EUA 
passaram a operar dentro da burocracia estatal brasileira, sendo uma grande afronta à soberania nacional, visto que esses técnicos estrangeiros prezavam pelos lucros e interesses particulares de seu país.

Conclui-se, que apesar do real interesse dos técnicos da Usaid em melhorar o sistema produtivo brasileiro por meio da ciência, tecnologia e educação, a "subordinação" brasileira aos interesses tecnológicos e dependência financeira estrangeira resultou em medidas antissociais e antinacionais, corroborando para o contemporâneo processo de reversão neocolonial.

Por fim, compreende-se neste estudo que foram as agências estatais brasileiras (Esalq/USP) e dos Estados Unidos (Usaid/OSU) que deram as bases científicas, educacionais e técnicas para a constituição do Agronegócio no Brasil.

\section{REFERÊNCIAS}

ARAPIRACA, José Oliveira. A Usaid e a educação brasileira: um estudo a partir de uma abordagem crítica da teoria do capital humano. Campinas, SP: Editora Autores Associados, 1982.

ARAÚJO, José Carlos Souza; GATTI JR., Décio (Org.). Novos temas em história da educação brasileira. Instituições escolares e educação na imprensa. Campinas, SP: Autores Associados/Uberlândia, MG: Edufu, 2002.

AYERBE, Luís Fernando. Estados Unidos e América Latina: construção da hegemonia. São Paulo: Editora Unesp, 2002.

BARGER, E. L. et al. Tratores e seus motores. São Paulo: Ed. Edgar Blucher, 1966.

CAPDEVILLE, Guy. O Ensino Superior Agrícola no Brasil. Viçosa, MG: Imprensa Universitária (UFV), 1991.

CARVALHO, Paulo C. Torres. Departamento de Fitopatologia. In: QUEIROZ, Luis Vicente de Souza. Esalq, 75 anos a serviço da Pátria. Edição comemorativa. Piracicaba: Esalq, 1975.

DREIFUSS, René Armand. 1964: A conquista do Estado - ação política, poder 
e golpe de classe. Petrópolis: Editora Vozes, 1981.

ESALQ 75. Escola Superior de Agricultura “Luiz de Queiroz": 75 anos a serviço da Pátria (1901-1976). Edição comemorativa. Piracicaba: Esalq, 1975.

FERNANDES, Florestan. A condição de sociólogo. São Paulo: Hucitec, 1978.

FGV. Centro de Pesquisa e Documentação de História

Contemporânea do Brasil (CPDOC). Ponto IV. Disponível em:

http://www.fgv.br/cpdoc/acervo/dicionarios/verbete-tematico/ponto-iv. Acesso em: out. 2017.

FICO, Carlos. O grande irmão: da operação Brother Sam aos anos de chumbo. O governo dos Estados Unidos e a ditadura militar brasileira. Rio de Janeiro: Civilização Brasileira, 2008.

FOUR-H. 4-H.org, National 4-H Council. Program of our nation's Cooperative Extension System and USDA. 2016. Disponível em: www.4h.org. Acesso em: ago. 2016.

GRAZIANO DA SILVA, José. Modernização dolorosa: estrutura agrária, fronteira agrícola e trabalhadores rurais no Brasil. Rio de Janeiro: Zahar Editores, 1982.

HOBSBAWN, Eric. A era dos impérios, 1875-1914 • 13. ed. São Paulo: Paz e Terra, 2004.

IANNI, Octavio. Ditadura e agricultura. Rio de Janeiro: Civilização Brasileira, 1979.

LEACOCK, Ruth. Requiem for revolution. The United States and Brazil, 1961-1969. Kent: The Kent State Press, 1990.

LENIN, Vladimir Ilitch. O imperialismo: fase superior do capitalismo. 4. ed. São Paulo, SP: Global, 1987.

MALAVOLTA, Eurípedes. A Escola Superior de Agricultura "Luiz de Queiroz" da Universidade deSão Paulo - Passado, Presente e Futuro. In: Esalq 75 (1901-1976). 75 anos a serviço da pátria. Edição comemorativa. Piracicaba: Esalq, 1975.

MICELI, Sérgio (Org.). A Fundação Ford no Brasil. São Paulo: Fapesp/Sumaré Idesp, 1993.

MÉSZÁROS, István. O poder da ideologia. São Paulo: Boitempo, 2004. 
MOTTA, Rodrigo P. Sá. As universidades e o regime militar: cultura política brasileira e modernização autoritária. Rio de Janeiro: Zahar, 2014.

MOORE JUNIOR, Barrington. As origens sociais da ditadura e da democracia: senhores e camponeses na construção do mundo moderno. São Paulo: Martins Fontes, 1975.

MOLINA, Rodrigo Sarruge. Ditadura, agricultura e educação: a Esalq/USP e a modernização conservadora do campo brasileiro (1964 a 1985). 2016. Tese (Doutorado) - Faculdade de Educação, Universidade Estadual de Campinas, Campinas, 2016. Disponível em: http:// repositorio.unicamp.br/jspui/handle/REPOSIP/321628. Acesso em: 20 jan. 2018.

SANFELICE, José Luís; JACOMELI, Maria Regina Martins; PENTEADO, Ana Elisa de Arruda (Org). História de instituições escolares. Bragança Paulista, SP: Margem da Palavra, 2016.

SILVA, Claiton Marcio da. Ciência e nação: Nelson Rockefeller, o Ibec Research Institute (IRI) e os caminhos da ocupação do Cerrado brasileiro (1946-1980). In: Simpósio Nacional de História - ANPUH, 26, 2011. São Paulo. Anais... São Paulo: Anpuh, 2011. Disponível em: http://www.snh2011.anpuh.org/resources/anais/14/1312801460_ARQUIVO_T extoparaANPUH.pdf. Acesso em: nov. 2014.

USAID/Esalq. Relatório semestral entre a United States Agency for International Development - Ohio State University e a Escola Superior de Agricultura "Luiz de Queiroz" da Universidade de São Paulo. Documento USP sob matrícula n. 65.1.8788.1.o, caixa 2868. Piracicaba, 1964.

USP. Documento oficial da USP sob guarda do arquivo protocolo do prédio central da Esalq/USP. Ofício sob a matrícula: no 88.1.112.118, 1988.

USP/Esalq. Relatório Anual de 1968 da Escola Superior de Agricultura "Luiz de Queiroz" da Universidade de São Paulo. Acervo da Biblioteca Central da Esalq, Piracicaba, 1968. 
RODRIGO SARRUGE MOLINA é professor da Universidade Federal do Espírito Santo (UFES), em Vitória/ES. Possui mestrado e doutorado em Educação pela Universidade Estadual de Campinas.

E-mail: molinaprof@hotmail.com

(1) http://orcid.org/0000-0002-4033-6049

Recebido em: 08 de novembro de 2017

Aprovado em: 22 de abril de 2019
(c) (i)
Revista História da Educaç̃̃o - RHE
Associação Sul-Rio-Grandense de Pesquisadores em História da Educação - Asphe
Artigo de acesso aberto distribuído nos termos de licença Creative Commons. 